\title{
Investigating Long-Distance Exploding-Wire Restrike
}

\author{
Rowan Sinton, Ryan van Herel, Wade Enright, and Pat Bodger
}

\begin{abstract}
An experimental setup was built using commonly available high-voltage laboratory equipment to investigate the creation of exploding-wire restrikes up to $9 \mathrm{~m}$ long. Sets of voltage traces are presented with varying applied average electric fields. Restrikes (formation of plasma paths) have been found to occur in a region of average electric field between 5.6 and $15 \mathrm{kV} / \mathrm{m}$. The average electric field of this region of restrikes is relatively low and will assist in investigation of novel plasma conductor configurations.
\end{abstract}

Index Terms-Exploding wire (EW), plasma generation, restrike.

\section{INTRODUCTION}

$\mathbf{E}$ XPERIMENTAL research at the University of Canterbury is presently investigating the use of exploding wires (EW) to create conductive plasma paths with commonly available high-voltage laboratory equipment. Applications envisaged, such as plasma coils [1], require that these conductive plasma paths are made as long as possible. A prototype plasma coil (Fig. 1) required a conductive plasma path that is $3 \mathrm{~m}$ in length. The mechanism that forms the conductive plasma path, called restrike, is the focus of the investigations presented in this paper.

Restrike is a well-known EW phenomenon and has been the focus of many EW experiments since the 1950s [2]. After a wire has gone through a melting and vaporization process and occasionally on an extended period of virtually no conduction (called the dwell time [3]), there exists a possibility of a highly conductive plasma-path formation (i.e., restrike). It has been suggested that the existence of restrike can be categorized by the average electric field applied to the wire [4], a technique also applied to results presented in this paper. Average electric field is defined as the initial voltage divided by the EW length. To date, EW studies have focused on short lengths of wire (usually much less than $1 \mathrm{~m}$ ), so restrikes are initiated with relatively high average electric fields (usually above $30 \mathrm{kV} / \mathrm{m}$ and as much as $1000 \mathrm{kV} / \mathrm{m}$ ).

The authors of this paper are interested in obtaining long EW restrikes. EW lengths from 1 to $9 \mathrm{~m}$ and voltages from 10 to $60 \mathrm{kV} \mathrm{dc}$ are used, resulting in average electric fields of less than $30 \mathrm{kV} / \mathrm{m}$. An experimental setup was built at the Univer-

Manuscript received October 20, 2009; revised December 6, 2009. First published March 8, 2010; current version published April 9, 2010.

The authors are with the Electrical and Computer Engineering Department, University of Canterbury, Christchurch 8140, New Zealand (e-mail: rowan.sinton@gmail.com; rmh83@student.canterbury.ac.nz; w.enright@elec. canterbury.ac.nz; pat.bodger@elec.canterbury.ac.nz).

Color versions of one or more of the figures in this paper are available online at http://ieeexplore.ieee.org.

Digital Object Identifier 10.1109/TPS.2010.2042080

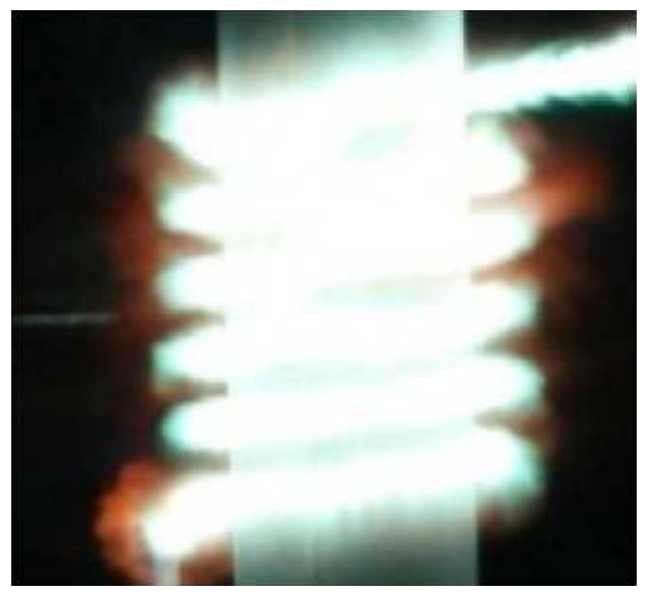

Fig. 1. Five-turn plasma coil created at the University of Canterbury highvoltage laboratory. The EW was a $0.27-\mathrm{mm}$ enameled copper wire wound around a 162-mm diameter former, with $35 \mathrm{kV}$ dc supplied from a 21.4- $\mu \mathrm{F}$ capacitor bank.

sity of Canterbury with equipment specifications common to most high-voltage laboratories. The subsequent investigations provide a new set of EW data and observations.

\section{EXPERIMENTAL SETUP}

A capacitor bank of 20 oil-filled capacitors, with an overall rating of $60 \mathrm{kV} \mathrm{dc}$ and $21.4 \mu \mathrm{F}$, was used as an energy source [5]. Energies of up to $38.5 \mathrm{~kJ}$ were therefore possible and were observed in experiments to be delivered in times of less than $100 \mu \mathrm{s}$, resulting in currents of up to $30 \mathrm{kA}$.

A new switch had to be built for these experiments, as there were no commercial products or existing designs to fit the requirements particular to long-distance $\mathrm{EW}$. A three-electrode triggered spark gap (TSG) design was chosen, using two 4-cm spheres that are open to atmospheric air. The sphere gap was adjustable from 5 to $30 \mathrm{~mm}$ to cover the full voltage range [6]. The TSG achieved a very large operating range between the self-trigger voltage and the minimum voltage for reliable triggering. This is essential when dealing with high-powered explosive experiments as a self-trigger event can damage the high-voltage laboratory equipment. The TSG was designed and built to give reliable triggering down to capacitor voltages of as low as $10 \mathrm{kV}$ dc as well as minimizing the likelihood of selftriggering during capacitor bank charging to $60 \mathrm{kV} \mathrm{dc}$.

A $30-\mathrm{k} \Omega$ water resistor was added to the wire side of the TSG, such that ionization of the main gap would be maintained even during the long dwell times (up to $200 \mu \mathrm{s}$ ). Two $10-\mathrm{m}$ long $95-\mathrm{mm}^{2}$-diameter cables were used as the return path for 


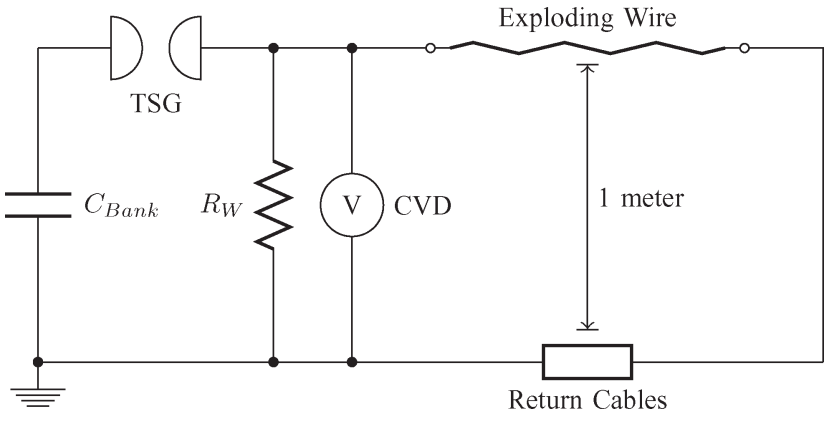

Fig. 2. Schematic of the experimental setup. $R_{W}$ denotes the $30-\mathrm{k} \Omega$ water resistor.

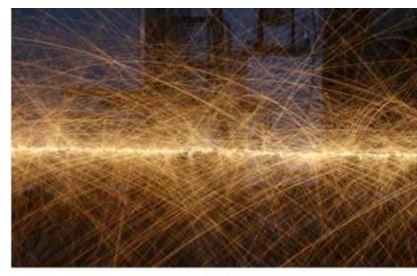

(a)

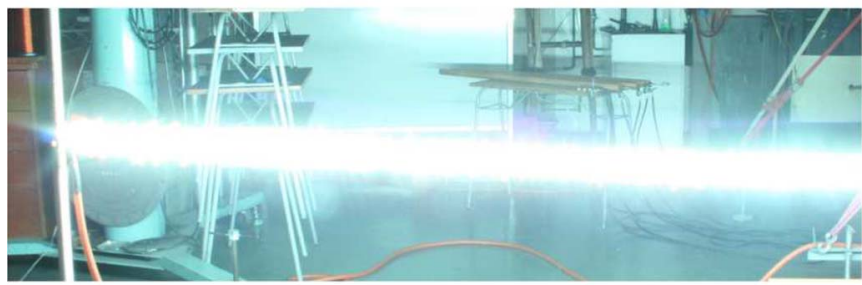

(c)

Fig. 3. Three observed outcomes of EW. (a) Liquid copper. (b) Beads of plasma. (c) Full plasma path.

the experiments. Wires were run in a straight path, which is $1 \mathrm{~m}$ above the ground. A capacitive voltage divider was used to record voltage traces. The EW test circuit is shown in Fig. 2.

One set of experiments, using 1.05-m-long wires, was performed at the Institute of High Voltage Engineering and System Management at the Graz University of Technology, Austria. Access to the Graz laboratory provided an opportunity to measure the electrical current flow during EW experiments. The University of Canterbury laboratory does not have this facility. The energy supply was a 200-kV Haefely current impulse generator, configured to have a capacitance of $20 \mu \mathrm{F}$. Voltage measurement was provided by a $2-\mathrm{k} \Omega$ resistive voltage divider, which also assisted in maintaining spark-gap ionization. Current was measured using a Pearson current transformer (model 1330). The EW length in the Graz experiments was limited to just over $1 \mathrm{~m}$.

\section{RESUltS AND Discussions}

The EW experiments completed by the authors have been observed to result in one of three outcomes (Fig. 3). When the average electric field is low, the explosion ejects liquid copper from the wire, and most of the voltage remains on the capacitor bank. As the average electric field is increased, increasing numbers of small beads of bright plasma form in discrete locations along the wire (similar plasma formations have been observed by Taylor [7]). Once the threshold of

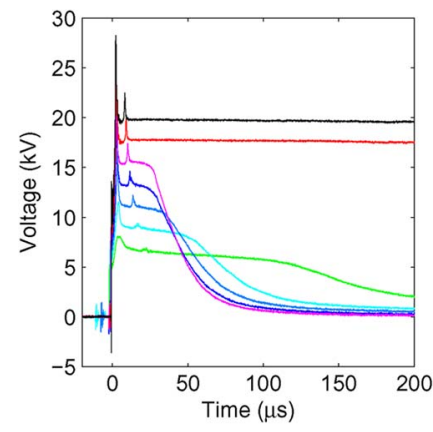

(a)

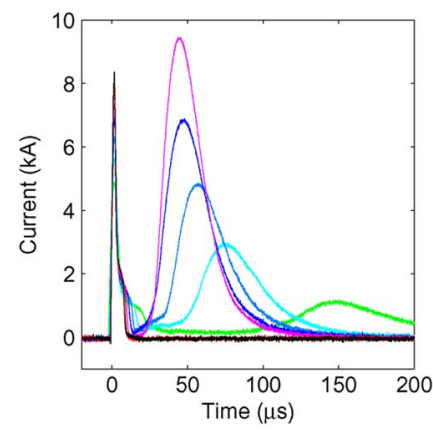

(c)

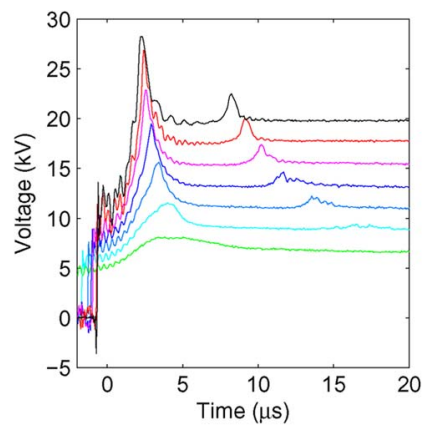

(b)

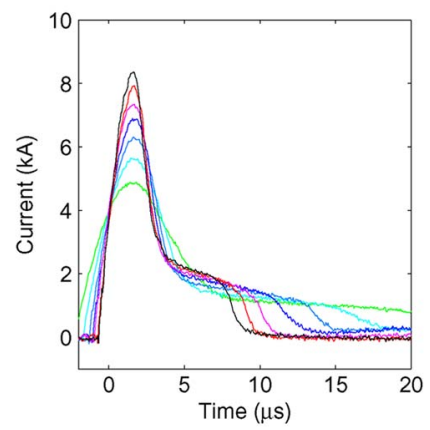

(d)
Fig. 4. Voltage and current traces for 1.05-m-long 0.2-mm-diameter wires exploded at voltages of 8 to $20 \mathrm{kV}$ dc (average electric fields of 7.6 to $19 \mathrm{kV} / \mathrm{m}$ ). (a) Complete waveform. (b) Detail of first $20 \mu \mathrm{s}$. (c) Complete waveform. (d) Detail of first $20 \mu \mathrm{s}$.

average electric field is exceeded, a continuous extremely bright column of plasma forms along the path of the wire, and the capacitors are completely discharged, indicating that restrike has occurred.

Sets of enameled copper wires were exploded using initial capacitor voltages from 8 to $60 \mathrm{kV}$ dc. In a set of 5-m-long 0.27-mm-diameter wires (Fig. 6), four of the wires - those at voltages of 35 to $50 \mathrm{kV} \mathrm{dc}$-were observed to restrike. This restriking condition is evident visually and in the voltage traces as a near-complete capacitor discharge after the dwell time. Similarly, in a set of 3-m-long 0.2-mm-diameter wires (Fig. 5), the restriking condition was seen in ten wires with voltages between 18 and $40 \mathrm{kV}$ dc. An upper limit of voltage in the 9-m-long set (Fig. 7) was not seen, as the voltage rating of the capacitor bank was reached. A lower restrike limit was not seen in the 1.05-m-long set (Fig. 4), as the lowest voltage which could be triggered using the Haefely triggered spark gap was $8 \mathrm{kV}$ dc. Each voltage trace shown in Figs. 4-7 are individual experimental results. The EW experiments are repeatable; other than minor electrical noise, the wave shapes of repeated tests appear the same.

The interesting commonality between these four sets is the range of average electric fields at which the restrikes occur. As summarized in Table I, the lowest and highest average electricfield values of each set are in some agreement. This is despite the very different wire diameters and lengths. Another researcher has reported similar low average electric field restrike values, using much shorter lengths of enameled wire [8].

All of the sets (except the 9-m-long set, for reasons stated earlier), show that restrike fails to occur once the voltage is increased too far, generally above $10-15 \mathrm{kV} / \mathrm{m}$. In 20 experiments 


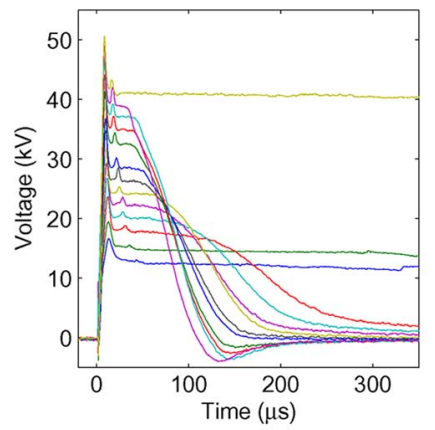

(a)

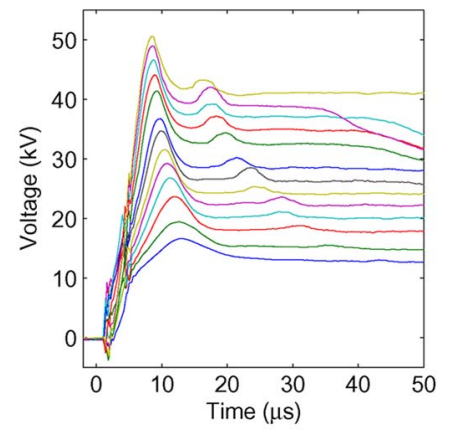

(b)
Fig. 5. Voltage traces for 3-m-long 0.2-mm-diameter wires exploded at voltages of 15 to $42 \mathrm{kV} \mathrm{dc}$ (average electric fields of 5 to $14 \mathrm{kV} / \mathrm{m}$ ). (a) Complete waveform. (b) Detail of first $50 \mu \mathrm{s}$.

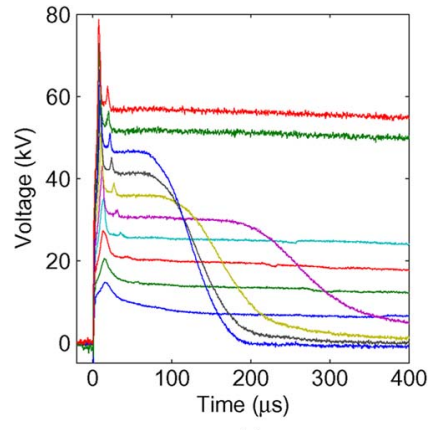

(a)

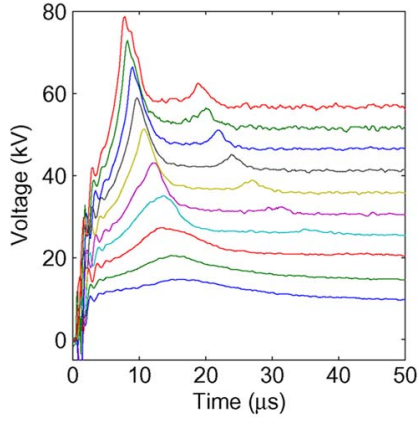

(b)
Fig. 6. Voltage traces for 5-m long 0.27-mm-diamter wires exploded at voltages of 15 to $60 \mathrm{kV}$ dc, giving average electric fields of 3 to $12 \mathrm{kV} / \mathrm{m}$. (a) Complete waveform. (b) Detail of first $50 \mu \mathrm{s}$.

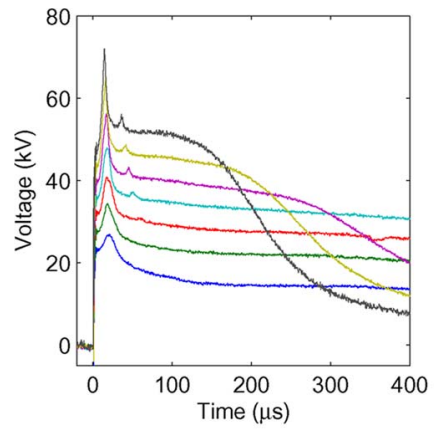

(a)

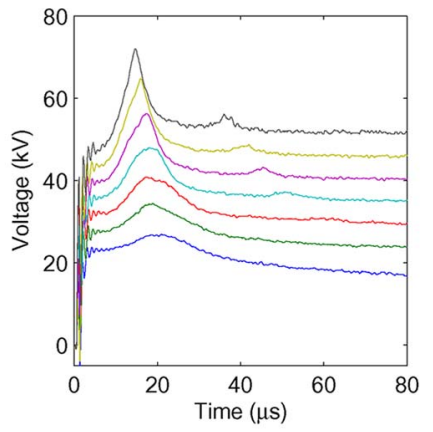

(b)
Fig. 7. Voltage traces for 9-m-long, 0.375-mm-diameter wires exploded at voltages of 30 to $60 \mathrm{kV}$ dc, giving average electric fields of 3.3 to $6.7 \mathrm{kV} / \mathrm{m}$. (a) Complete waveform. (b) Detail of first $80 \mu \mathrm{s}$.

TABLE I

SuMmary of Wire EXPERIMENTS, StATING THE LOWEST AND Highest AVERage Electric-Field Values Which Resulted in Restrike

\begin{tabular}{|c|c|c|c|}
\hline $\begin{array}{c}\text { Length } \\
(\mathrm{m})\end{array}$ & $\begin{array}{c}\text { Diameter } \\
(\mathrm{mm})\end{array}$ & $\begin{array}{c}\text { Lowest Restrike } \\
(\mathrm{kV} / \mathrm{m})\end{array}$ & $\begin{array}{c}\text { Highest Restrike } \\
(\mathrm{kV} / \mathrm{m})\end{array}$ \\
\hline 1.05 & 0.20 & N/A & 15.2 \\
3.0 & 0.20 & 5.7 & 13.3 \\
5.0 & 0.27 & 7.0 & 10.0 \\
9.0 & 0.375 & 5.6 & N/A \\
\hline
\end{tabular}

with average electric field between 15.2 and $30 \mathrm{kV} / \mathrm{m}$, using various wire diameters, lengths, and voltages, none have been observed to restrike. This is not an intuitive result; the expecta- tion for electrical breakdown is that higher electric fields should allow for easier breakdown.

This paper presents EW for three different wire diameters. The only significant impact of using a larger diameter wire which has been observed is that the quantity of energy removed from the capacitors in the melting and/or vaporization process is increased. This can be calculated by noting the voltage reduction from the initial capacitor bank charge voltage to the voltage recorded during the dwell time. For most higher voltage tests, this energy reduction is negligible; however, if large wires and low voltages are used, it becomes prohibitive to creating favorable conditions for restrike.

\section{CONCLUSION}

An experimental setup has been constructed in the highvoltage laboratory at the University of Canterbury and used for the investigation of EW restrikes up to $9 \mathrm{~m}$ long. It was observed that restrikes occur in enameled copper wires with applied average electric fields over $5.6 \mathrm{kV} / \mathrm{m}$. This result is consistent with many experiments using various EW diameters and lengths. When the average electric field exceeded around 10 to $15 \mathrm{kV} / \mathrm{m}$, however, the restrikes failed to initiate. No restrikes have been observed between 15.2 and $30 \mathrm{kV} / \mathrm{m}$.

The identified region of restrikes, categorized by average electric fields between 5.6 and $15 \mathrm{kV} / \mathrm{m}$, allows the creation of long conductive plasma paths in the laboratory environment using relatively low voltages and commonly available highvoltage equipment. This is encouraging because it demonstrates that other high-voltage laboratories are already equipped to investigate plasma conductor paths over long distances and in novel configurations, e.g., coils.

\section{ACKNOWLEDGMENT}

The authors would like to thank J. Lawrence (Electric Power Engineering Centre) for his support; J. Woudberg, K. Smart, and D. Healy for their technical support; and the staff at the Institute of High Voltage Engineering and System Management, Graz University of Technology, Austria, for the provided advise, assistance, and use of equipment.

\section{REFERENCES}

[1] R. Sinton, C. Hammond, W. Enright, and P. Bodger, "Generating high voltages with a plasma coil transformer," in Proc. Techcon Asia Pacific, Sydney, Australia, 2009, pp. 211-219.

[2] W. G. Chace and H. K. Moore, Exploding Wires. New York: Plenum, 1959.

[3] A. E. Vlastós, "Dwell times of thin exploding wires," J. Appl. Phys., vol. 44, no. 5, pp. 2193-2196, May 1973.

[4] A. E. Vlastós, "Restrike mechanisms of exploding wire discharges," J. Appl. Phys., vol. 39, no. 7, pp. 3081-3087, Jun. 1968.

[5] D. Smith, W. Enright, and P. Bodger, "A test circuit for long distance directional plasma discharge using the exploding wire technique," in Proc. 15th Int. Symp. High Voltage Eng. (ISH), Ljubljana, Slovenia, 2007.

[6] Voltage Measurement by Means of Standard Air Gaps, AS60052, 2005.

[7] M. J. Taylor, "Formation of plasma around wire fragments created by electrically exploded copper wire," J. Phys. D, Appl. Phys., vol. 35, no. 7, pp. 700-709, Apr. 2002.

[8] B. K. Bhat and I. B. Jordan, "Explosion of bare and insulated copper wires," J. Appl. Phys., vol. 42, no. 2, pp. 809-814, Feb. 1971. 


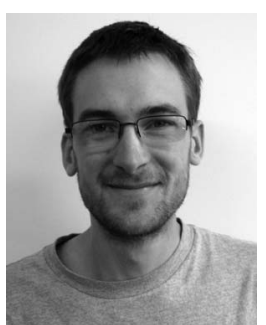

Rowan Sinton received the B.E. (Hons) degree in electrical engineering from the University of Canterbury, Christchurch, New Zealand, in 2007, where he is currently working toward the Ph.D. degree.

His research interests are applications of high voltage and novel electrical machinery.

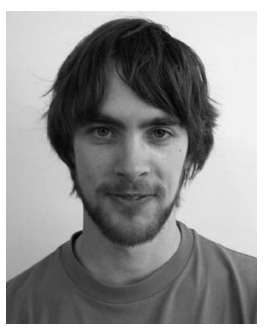

Ryan van Herel received the B.E. (Hons) degree in electrical and electronic engineering from the University of Canterbury, Christchurch, New Zealand, in 2008, where he is currently working toward the M.S. in engineering degree.

His research interests are high-voltage engineering and novel electrical machinery.

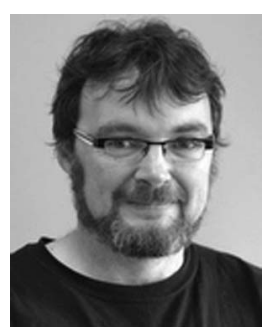

Wade Enright received the B.E. (Hons) and Ph.D. degrees in electrical and electronic engineering from the University of Canterbury, Christchurch, New Zealand, in 1992 and 1995, respectively.

During 1996, he was with the Manitoba HVDC Research Centre, Winnipeg, Canada. He is currently a Senior Lecturer with the University of Canterbury. $\mathrm{He}$ also offers electrical engineering services to the industry via his own company "Viva." He specializes in power transformers and high voltage.

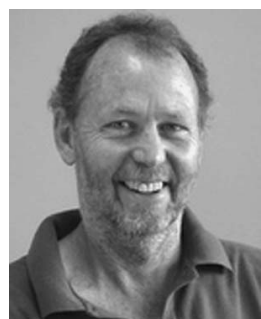

Pat Bodger received the B.E. (Hons) and Ph.D. degrees in electrical engineering from the University of Canterbury, Christchurch, New Zealand, in 1972 and 1977, respectively.

From 1977 to 1981, he was with the Electricity Division, Ministry of Energy, New Zealand. He is currently Head of the Power Group, Department of Electrical and Computer Engineering, University of Canterbury, where he is also Director of the Electric Power Engineering Centre. 